\title{
Presenting an Executive Model for Improving the Performance of Sports Federations
}

\author{
${ }^{1}$ Elham Fasanghari ${ }^{*},{ }^{2}$ Mahmood Goodarzi, ${ }^{3}$ Rahim Ramezaninezhad, \\ ${ }^{1}$ Mohammad Hossein Ghorbani
}

${ }^{1}$ Department of Sport Management, Sport Sciences Research Institute, Tehran, Iran. ${ }^{2}$ Department of Sport Management, Faculty of Sport Sciences, University of Tehran, Tehran, Iran. ${ }^{3}$ Department of Sport Management, Faculty of Sport Sciences, University of Guilan, Guilan, Iran.

\begin{abstract}
Background. Considering the position and importance of sports federations in Iran and their very important duties and dependence on the Ministry of Sports and Youth in terms of financial resources, they must be responsive to their performance in providing services and implementing their programs. The duties are namely the development and promotion of sports at the public and championship levels, coordination of competitions at the local and national levels, selection of athletes, and training and development of national teams for participation in the international fields. Therefore, there is a growing need for a practical framework to improve the performance of sports federations. Objectives. The purpose of this study was to present an executive model for improving the performances of sports federations. Methods. Considering the qualitative and exploratory nature of the subject, the grounded theory was applied as a qualitative research method using the Glaser model. First, a preliminary list of effective factors was identified through primary studies. It was followed by semi-structured interviews conducted with 25 elites who were aware of the subject of the study. Results. The open coding results denoted that 83 indicators could improve the performances of the Iranian sports federations. At the axial coding stage, the indicators were classified into 19 concepts. Finally, the five categories of "management and leadership," "resources," "specific performance of federation," "information and communication," and "education and research affairs" were identified through selective coding. Conclusion. "Discovering and Growing the Talents", Legal and Ethical Issues", Interaction and collaboration with other organizations and institutions", Training and Promotion human resources including coaches and referees" and "Organizing National Teams" are concepts that improve the performance of sports federations, and managers should pay attention to them.
\end{abstract}

KEY WORDS: Sports Federations, Performance Improvement, Performance Management, Qualitative Research.

\section{INTRODUCTION}

There is intense competition in today's world. Therefore, it is necessary to have speed and volume of information, challenges to be faced by organizations, and some criteria to determine the status of organizations and planning based on their strengths and weaknesses. A highly competitive atmosphere was created among organizations and endless endeavors were made. These were done to improve the quality of services and products and meet customer expectations and needs. This led

*. Corresponding Author:

Elham Fasanghari

E-mail: elhamfasanghari@gmail.com 
them to seek a comprehensive, reliable, and flexible approach to evaluate their performances. Moreover, this helped them to obtain accurate and comprehensive information about their position, status, and performance in society. Moreover, they will be able to prevent further errors in future and thereby guarantee their own lives by considering their past strengths and weaknesses (1).

If organizations want to survive and make their presence felt in both national and global arenas, they are required to focus on the principle of continuous improvement. This principle can be achieved only by improving the performance management. Performance management can be improved by receiving the necessary feedback from the inner and outer environment, analyzing the strengths and weaknesses and the opportunities and threats of an organization, accountability, and considering the needs and expectations of customers and beneficiaries through the creation and implementation of some applicable indicators using an appropriate pattern.

Continuous improvement in all aspects of the business is essential for meeting the challenge of today's turbulent environments (2). But the mechanisms whereby such a continual stream of innovation can be achieved are often less clearly identified (3).

One of the important pillars of a country's sports is the presence of sports federations. The outcome of their performance determine the sports performance of that country. Considering the position and importance of sports federations in Iran and their very important duties and dependence on the Ministry of Sports and Youth in terms of financial resources, they must be responsive to their performance in providing services and implementing their programs. The duties are namely the development and promotion of sports at the public and championship levels, coordination of competitions at the local and national levels, selection of athletes, and training and development of national teams for participation in the international fields. Therefore, there is a growing need for a practical framework to improve the performance of sports federations.

The necessity and importance of performance evaluation for the continuous improvement of an organization and performance management is an obvious matter. Some research works were conducted in this regard. A few of the studies conducted in the field of sports organizations are given in the following.

Rodríguez Bolívar, López Hernández and Ortiz Rodríguez (2010); Walmsley (2012) and Dimitropoulos, Kosmas and Douvis (2017) were among the researchers who introduced new applied research into the implementation of a balanced scorecard assessment methodology in sports organizations (4-6). However, their method pertained to internal assessment. Since each organization has its own strategic plan, it does not have the capability to implement a methodology for several sports federations. A number of studies, including Papadimitriou and Taylor (2000); Shilbury and Moore (2006) and Eydi, Ramzaninezgad, Yosefi, and Malekakhlagh (2014) considered the effectiveness of sports organizations and evaluated their performance with this approach (7-9). In addition, Honari, Mohammadi, Ghafori, and Afshari (2013); Mirfakhredini, Peymanfar, Oghada, and Alimohammadi (2013); Nezad Sajadi and Soleimani Damaneh (2014); Solntsev and Osokin (2018) and Torres, Martin and Guevara (2018) tried to do evaluation by identifying strengths and weaknesses of the performance of the sports organizations for better improvement (10-14).

O'Boyle and Hassan (2014); Geeraert, Alm and Groll (2014) and Nagel, Schlesinger, Bayle and Giauque (2015) investigated performance management and performance measurement in sports organizations with a performance improvement approach (15-17).

However, only Ruoranen et al. (2016) designed an assessment system for evaluating the performance of sports federations and O'Boyle (2014) developed a performance management framework for a national sport organization $(18,19)$.

Most of the research mainly focused on the performance evaluation. Moreover, a limited number of studies were conducted on designing a model for the performance assessment of federations. More attention has been paid to the quantitative indicators, and sometimes to the results. None of the studies have provided practical solutions for improving the performance in sports federations. Although performance evaluation somehow identifies the strengths and weaknesses of the federations, it is very important for them to have a framework with complete and comprehensive indicators. These indicators guide 
the federations and allow them to reach the desired outcomes. Therefore, recognizing methods for improving the organizational performance is an important issue that should be considered. This should be done by adopting a human-centered approach, based on the strategic management thinking and targeting management practices with objective and practical approaches.

The results of some studies on determining various criteria and indicators for the performance assessment were considered. Moreover, the existing theoretical foundations and opinions of experts and authorities on the subject were taken into account. Taking these issues into consideration, the present study aims to determine some criteria and indicators for the evaluation of Iran's sports federations, keeping in mind the environment, conditions, and other characteristics of federations. These indicators show what and how a federation should perform in order to achieve its key and important results in all aspects, in other words, to achieve an optimal level of performance.

\section{MATERIALS AND METHODS}

Research Method. This study was a qualitative research, in which the grounded theory method was applied for conducting the study. The grounded theory includes various approaches. In this study, the emergent method, associated with the work of Glaser, was applied for data analysis (20).

Qualitative research is well suited for "why", "how" and "what" questions about human behavior, motives, views and barriers. Thus, with its mainly inductive approach qualitative research is suitable for problem identification, hypothesis generation, theory formation and concept development (21).

Qualitative description focuses on providing 'straight' descriptions of events or perceptions with low inference interpretation (22).

Instrument and Data Collection. Qualitative researches use the data obtained from the interviews, documentation, observations, etc. to understand and explain the social phenomenon. In the first stage of the study, the preliminary list of predictor factors was identified by reviewing relevant literature and collecting information from the library. The preliminary list was considered as the interview questions and the primary tool for collecting data. Then the interview guide was developed and the researcher sent it to the elite before the interview.

The data collection tool in this study included the semi-structured interviews, which were conducted with 25 elites who were aware of the subject of the study. The duration of the interviews was different but they lasted, on average, $45 \mathrm{~min}$. The place of the interview was agreed upon by the interviewee and researcher.

Participants. The theoretical sampling method was used in the present study; the interviews continued until theoretical saturation. A total of 25 participants ( 21 male, 5 female, M age $=47$ years) participated in this study. The interviewees included six experts from the Performance Evaluation Office of the sports federations in the Ministry of Sports, 10 senior managers and evaluators from the sports federations, and nine academic elites who were aware of the subject of the study. Their level of education was as follows: $\mathrm{PhD}$ (11 people), master's degree ( 9 people) and bachelor's degree (5 people).

Statistical Analysis. After the interview, the analysis was done. In this way, after conducting and editing the interviews, different views were coded and classified in the same conceptual groups and analyzed qualitatively. The data were coded openly and axially in this research. Finally, the selective coding process was performed, based on the analysis of the factors derived from the open and axial coding processes.

\section{RESULTS}

The open coding results denoted that 83 indicators could improve the performances of the Iranian sports federations. At the axial coding stage, the indicators were classified into 19 concepts. Table (1) shows the results of open and axial coding. Finally, the five categories of "management and leadership," "resources," "specific performance of federation," "information and communication," and "education and research affairs" were identified through selective coding that table (2) shows the results.

Finally, the following theoretical model was developed by finding the final relationships between the categories derived from the selective coding. (figure1). After developing the model and 
to increase its validity, the final model was presented to the experts. The experts were familiar with both the performance management and the qualitative method. Most of these individuals approved the model, and some of them had some corrective comments, which were made in the back and forth process. However, the corrections were applied in the final model.

\section{DISCUSSION}

For decades, researchers have recognised the power of sport as a social and economic development tool (23). This belief is a fundamental reason why governments and key stakeholders invest in and support sport systems that deliver social or community outcomes (24). Recently, sport organisations, leagues, teams, and brands have been using sport in a strategic manner to engage various groups in socially desirable behaviours, in an effort to contribute to community development agendas, such as health, positive youth development, and education (25).

The importance of sports in today's world is clear, so the responsible organizations, including the sports federations, must have strategies to improve their performance that can play their role properly.

The purpose of this study was to present an executive model for improving the performances of sports federations. The open coding results denoted that 83 indicators could improve the performances of the Iranian sports federations. At the axial coding stage, the indicators were classified into 19 concepts. Finally, the five categories of "management and leadership," "resources," "specific performance of federation," "information and communication," and "education and research affairs" were identified through selective coding.

Management and Leadership component forms the mastermind of the sports system. Its task is to coordinate and link the resources and the cycle of processes, so as to produce the ultimate product and achieve the goals of the sports system. The strategies for improving the performance of sports federations with regard to the management and leadership category included "developing, implementing, and monitoring the performance assessment system in accordance with the activities of the federations"; "continuous review of the federation's plans and strategies"; "setting strategic plans (long-term) through taking into account the needs"; "coordination and alignment of the federation's structures, programs, projects, and actions with the developed strategies"; "the speed and agility of senior managers in responding to the environmental changes"; "preparing the ground for developing creativity and innovation in the human resources"; "utilizing the responsive and accountable individuals and teams"; "using the views and specialties of employees in decision making process"; and "the commitment of the senior managers of the federation to the strategic plan."

An important aspect of any performance management system is indeed performance measurement - constant monitoring of organisational dimensions relevant to the performance management system. Measurement is the process of providing data to examine where behaviours can be altered to facilitate improved performance (15). The literature suggests that performance measurement systems can function as structural solutions for the different institutional demands (26).

Wemmera, Emrich and Koenigstorfer (2016) said that focusing on Strategies understanding and responding to the strengths and weaknesses of organizations is important (27).

Resources formed the next category identified in this research. It included all the human, financial, building, equipment, materials and natural, technological, information and knowledge resources. All these resources must be managed in order achieve sustainable success. The performance improvement strategies associated with the component of resources were "placing importance on the discipline and financial transparency"; "emphasizing the preservation and development of communication and interaction with the financial sponsors, banks, and other sources of financing"; "development of the federation's sports equipment"; "standardization of the national and provincial sports facilities"; "development of the capabilities and competencies of the human resources in the federation in accordance with the needs and strategic requirements"; "strengthening and motivating human resources to achieve strategies"; and "enjoying the efficient compensation and welfare systems." 
The concepts of human capital and strategic management of human resources are very common in the organizations in terms of philosophy and technique. The term of "human capital" is considered as a key element in improving the assets of an organization, since it is a sustainable competitive advantage and increases the employees' efficiency. Some organizational theorists apply the rules of human capital theory to prove the ability to create useful competitions between companies by means of developing individual human resources (28). Eydi, Ramzaninezgad, Yosefi and Malekakhlagh (2014) for measuring effectiveness in sporting federations introduced indicators included "The organization is able to acquire funds from a variety of sources", "The organization has adequate facilities" and "The organization is able to acquire funds from a variety of sources".

Specific performance of federation was also among the identified categories in this study. The important indicators related to this category were "holding festivals and public recreational competitions"; "continuous emphasis on applying new methods of coaching and refereeing"; "using a knowledgeable nutritionist, bodybuilder, physiotherapist, massager, psychologist, and elite coaches in the national teams"; "establishing internal and external training camps in line with the latest patterns"; "designing and implementing a curriculum to explore, attract, cultivate, and develop the sports talents"; "establishing active talent identification bases"; "designing and implementing anti-corruption programs in sports, fighting against brokerage, etc."; and "placing emphasis on the observance of legal issues in the sports leagues and different competitions."

Ethics are the key components of sport integrity and guide the morals of individuals, teams and organisations in upholding good character. A significant factor to maintaining sport integrity is its culture. It is important that sport organisations prioritise ethical values and decision-making at all levels of their hierarchy. Maintaining a culture towards preserving integrity of sport has many benefits, including trust and support of a sport, as well as improved participation and retention rates, better financial sustainability due to increased sporting memberships, attracting sponsors and grants, and on-field success resulting from the appeal of being associated with a successful brand (29).

Sotiriadou \& Shilbury (2009) introduced talent identification as one of the key indicators in the development of sporting championships in various sports fields.

Information and communication was among the other strategies for improving performance of sports federations. This category included some indicators such as "the federation's relationship and cooperation with the Ministry of Sports, the National Olympic Committee, International Federation, and other organizations"; "hosting the federation's Asian and international meetings"; "useful and up-to-date notification to meet the clients' information needs"; and "the use of information and communication technology for continuous communication with the athletes and other beneficiaries and receiving their feedback."

Effective media relations and direct communication with customers are essential for all sports organizations. Successful managers in sports field must have a clear understanding of how Information and Communication Technology works to manage the communication process (30).

Education and research affairs formed the last category and could be considered as a series of systematic, targeted, and scientific endeavors. Therefore, this could rationalize and, as a result, make the various elements of the sports system more efficient. The strategies identified in this category included "holding human resource training courses at the federation and delegation level"; "holding the training, coaching, refereeing, justification, and upgrading courses"; "dispatching referees and coaches to the international courses"; "holding national and international scientific seminars and conferences"; and "publishing books, scientific and research journals and sports magazines, and conducting research projects."

Nowadays human capital can be considered as the main asset of any organization $(28,31)$, and it must be tried to educate and promote them. Eydi, Ramzaninezgad, Yosefi and Malekakhlagh (2014) in their research introduced the indicators of "appropriate training \& development courses for coaches" and "further training for professional staff" for the effectiveness of federations. 


\section{CONCLUSION}

Mission, goals and functions of sport are special, therefore, sport has an important place in the realization of development plans of countries. Today, sport is faced with increasing demand and it depends on government funding, it must be accountable to the state and society. Therefore, awareness of the current situation of sport is necessary by adopting appropriate strategies and it should give a clear answer to the demands of society and the government.

It should be noted that improving performance is one of the essential issues for gaining competitive advantage for sports organizations. Creating an efficient system for improving performance is one of the accepted strategies for knowing the current situation and the organization's improvement and excellence. This system should be tailored to the specific characteristics, conditions and context of the organization.

In line with the performance improvement, each system should have clear aims and objectives. It should be precisely developed by considering the specific culture and circumstances of the organization and the involvement of its managers and general employees. Every model selected and applied for this purpose (performance improvement) should be localized through training and conceptualization. In this way, you will enjoy a high level of continuous support of the organization. Providing a native model for improving the organizational performance of sports federations can be regarded as the main lesson of the present study. The uses of the wellknown and credible global patterns are justifiable and accepted. However, internal sports organizations will definitely get better results if they develop their management patterns by considering their particular circumstances and climates. Therefore, in this study a comprehensive approach was developed to provide some executive indicators and design a native model in order to improve the performance of sports federations.

Current system for assessing sports federations is limited to a number of evaluation forms that do not have the appropriate scientific and research support. Assessments in Iran have mainly been presented in the form of a paper or performance report, which mostly provide census and figures.
There is no transparent and coherent process of performance evaluation that can eliminate deficiencies and create incentives and provide the appropriate infrastructure for performance improvement. Therefore, the design of the native model is proposed to evaluate the performance of sports federations in proportion to their nature and characteristics for future research. So that this model can play an effective role in providing the demands and excellence of sports federations.

\section{APPLICABLE REMARKS}

- "Discovering and Growing the Talents", Legal and Ethical Issues", Interaction and collaboration with other organizations and institutions", Training and Promotion human resources including coaches and referees" and "Organizing National Teams" are concepts that improve the performance of sports federations, and managers should pay attention to them.

- The strategies for improving the performance of sports federations for Organizing National Teams Concept included" Continuous emphasis on applying new methods of coaching and refereeing", "Using a knowledgeable nutritionist, bodybuilder, physiotherapist, massager, psychologist, and elite coaches in the national teams" and "Establishing internal and external training camps in line with the latest patterns".

- The strategies for improving the performance of sports federations with regard to the Interaction and collaboration Concept included "Concluding Memorandum of Understanding (MOU) for cooperation with other organizations (such as the academic centers and universities, Ministry of Education, armed forces, research institutes, municipalities, etc.) for the development of sports" and "Active participation of the federation in sports (Asian and international)". 
Table 1. The Results of Open and Axial Coding

Concepts

\section{Monitoring and \\ Evaluation}

Pivotal Program

- Developing, implementing, and monitoring the performance assessment system in accordance with the activities of the federations

- Development, implementation, and monitoring of the performance assessment system and ranking the evaluation of each unit and department (committees, delegations, human resources, etc.)

- Emphasizing the use and consideration of national and international indicators in the evaluation of the federation

- Continuous review of the federation's plans and strategies

- Continuous monitoring of strategies and making necessary adjustments

- Collecting the progress report of programs (such as the talent identification programs, fighting against doping, tournament reporting, etc.), and their ongoing and regular evaluation

- Setting strategic plans (long-term) through taking into account the needs by the senior executives

- Emphasizing and focusing on the long-term programs and on the implementation of short-term programs by the senior executives

- Considering the opportunities and environmental threats in formulating the strategy of the federation

- Considering the strengths and weaknesses in developing the strategy of the federation

- Coordination and alignment of the federation's structures, programs, projects, and actions with the developed strategies

- Implementing the strategies of the federation through the formulation of goals, targets, operational plans, and different procedures

- Transferring the long-term and short-term programs to other employees and ensuring their understanding by the subordinates

- Codification of all the activities of the federation in a framework, including the executive processes and steps and complying with the regulations

- The speed and agility of senior managers in responding to the environmental changes

\section{Organizational Flexibility}

\section{Intra-organizational Collaboration}

- Preparing the ground for developing creativity and innovation in the human resources

- Providing the resources (human, financial, infrastructure, information, etc.) on time. The resources were required for the change in programs and putting them at the disposal of the executives

- Clarification of the missions and goals of the federation to the employees and society by the senior executives

- Senior executives' awareness of the model of progress and excellence and its role in the development

- Emphasizing institutionalization of the culture of success and victory among human resources

- Utilizing the responsive and accountable individuals and teams

- Strengthening the teamwork spirit among the human resources

- Using the views and specialties of employees in decision making process

- The possibility of easy and fast communication between the staff and managers

- Developing the culture of sharing knowledge and information, learning from the experiences, and self-reporting of errors (expressing your mistakes)

Principles of Value - The commitment of the senior managers of the federation to the strategic plan 
Table 1. The Results of Open and Axial Coding

Concepts Indication

- Revival and dissemination of fair qualities and athletic spirit among the athletes

- Identifying, understanding, and anticipating the needs and expectations of key beneficiaries (such as the Ministry of Sports, the International Federation, the National Olympic Committee, etc.)

- Identifying, understanding, and anticipating the needs and expectations of non-key beneficiaries (such as the society, government, legislators, etc.)

Current Situation $\quad$ Considering the quality and quantity of manpower in the formulation of the strategies and programs of the federation

- Considering the financial resources, facilities, and equipment available for the formulation of the strategies and programs

- Anticipation and management of all human, financial, material, and technological requirements for the realization of the strategy

- Funding the federation through the state and public institutions and investment of the state companies

- Reducing the financial burden through the investment of private companies, privatization, and the formation of national sports associations

Financial Resources

- Putting emphasis on the discipline and financial transparency

- Providing part of the financial resources in the expansion of marketing activities and diversification of income sources

- Emphasizing the preservation and development of communication and interaction with the financial sponsors, banks, and other sources of financing

- Saving energy and consumer goods

- Emphasizing the effective and efficient use of equipment and buildings and maximizing their productivity

Material Resources $\quad$ Development of the federation's sports equipment

- Building specialized places for sports

- Standardization of the national and provincial sports facilities

- Ensuring the alignment of human resources plans with the objectives, statements, missions, and vision of the federation

- Development of the capabilities and competencies of the human resources in the federation in accordance with the needs and strategic requirements

- Strengthening and motivating human resources to achieve strategies

- Improving the skills and competencies (technical, human, and perceptual) of the federation's employees

Human Resources $\quad$ Encouraging direct and effective communications and interactions between the employees and federation's beneficiaries

- Enjoying the efficient compensation and welfare systems

- Appreciation and support of human resources (executive agents, referees, and coaches)

- Putting emphasis on the importance of promotion and job enlargement in the employees

- Emphasizing the development of technology-based knowledge among the human resources

- Using of databases and internet platforms

Information

- Creation of the Information and Sports Statistics Unit and classification and maintenance of the relevant documents in it

- Providing sports ID cards for coaches, referees, athletes, champions, pioneers, and other professionals 
Table 1. The Results of Open and Axial Coding

Concepts Indication

- Emphasizing the use of statistics, information, and knowledge in any decision-making process

- Providing brochures and posters, holding exhibitions, conferences, and joint cultural programs with other organizations for cultural-sports development, and offering the

Culture Building products

- Holding festivals and public recreational competitions

- Using the mass media such as radio, TV, newspapers, news agencies, news sites, etc. for informing, promoting, and marketing

- The use of social networks such as Internet and interactive media, provided by the

Propagation mobile phones such as the Instagram and Telegram for informing, promoting, and marketing goals

- The use of new software and programs in different fields of work

- Continuous emphasis on applying new methods of coaching and refereeing

Organizing National • Using a knowledgeable nutritionist, bodybuilder, physiotherapist, massager, Teams psychologist, and elite coaches in the national teams

- Establishing internal and external training camps in line with the latest patterns

- Designing and implementing a curriculum to explore, attract, cultivate, and develop the

Discovering and sports talents

Growing the Talents

- Establishing active talent identification bases

- Designing and implementing anti-corruption programs in sports, fighting against

Legal and Ethical brokerage, etc.

Issues

- Placing emphasis on the observance of legal issues in the sports leagues and different competitions

- Cooperation of federation with the assessors and inspectors of the Ministry of Sports and the National Olympic Committee

- Concluding Memorandum of Understanding (MOU) for cooperation with other organizations (such as the academic centers and universities, Ministry of Education, armed forces, research institutes, municipalities, etc.) for the development of sports

Interaction and Collaboration

the federation's relationship and cooperation with the Ministry of Sports, the National Olympic Committee, International Federation, and other organizations

- Emphasizing the development of communication with the federation's beneficiaries

- Active participation of the federation in sports (Asian and international)

- Hosting the federation's Asian and international meetings

- Useful and up-to-date notification to meet the clients' information needs

- The use of information and communication technology for continuous communication with the athletes and other beneficiaries and receiving their feedback

- Holding human resource training courses at the federation and delegation level

- Developing a long-term education system for the federation and acting in accordance with the educational calendar

Training and Promotion

- Holding the training, coaching, refereeing, justification, and upgrading courses

- Holding training, preparation, retraining, testing, and stage workshops

- Dispatching referees and coaches to the international courses 
Table 1. The Results of Open and Axial Coding

Concepts Indication

Research and

- Holding national and international scientific seminars and conferences

Development

- Publishing books, scientific and research journals and sports magazines, and conducting research projects

Table 2. The Results of Selective Coding

\begin{tabular}{cl}
\hline \multicolumn{1}{c}{ Categories } & \multicolumn{1}{c}{ Concepts } \\
\hline \multirow{4}{*}{ Management and Leadership } & Monitoring and Evaluation \\
Pivotal Program \\
Organizational Flexibility \\
Intra-organizational Collaboration \\
Principles of Value \\
Current Situation
\end{tabular}

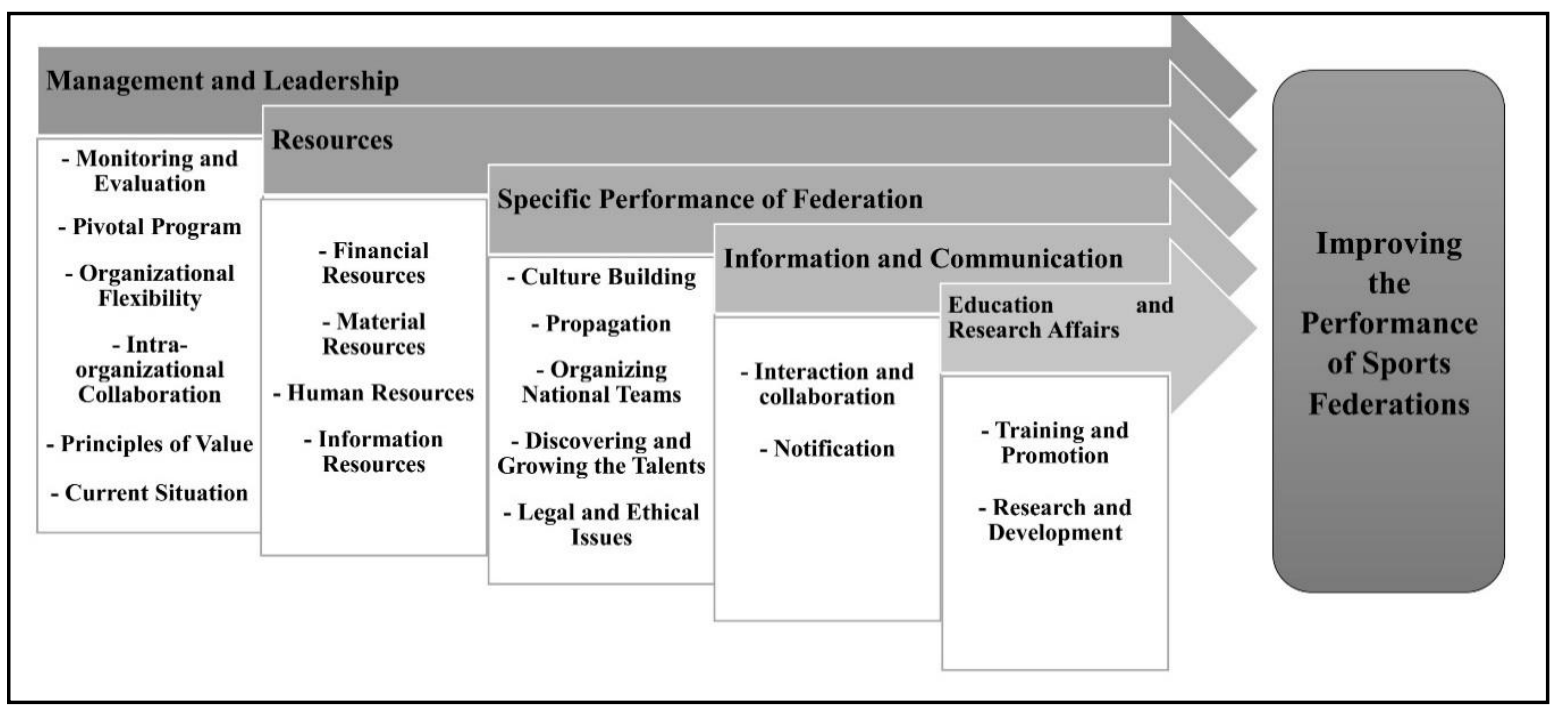

Figure1. Conceptual Model. 


\section{REFERENCES}

1. Sajadi HS, Hariri MH, Karimi S, Baratpour S. Performance Self Assessment by the Excellence Model in Different Hospitals of Isfahan University of Medical Sciences and Healthcare Services 2006. Research in Medicine. 2008;32( 3):227-31 [Article in Farsi].

2. Bessant J, Caffyn S. High-involvement innovation through continuous improvement. International Journal of Technology Management. 1997;14(1):7-28.

3. Bessant J, Caffyn S, Gallagher M. An evolutionary model of continuous improvement behaviour. Technovation. 2001;21(2):67-77.

4. Rodríguez Bolívar MP, López Hernández AM, Ortiz Rodríguez D. Implementing the balanced scorecard in public sector agencies: An experience in municipal sport services. Academia Revista Latinoamericana de Administración. 2010(45).

5. Walmsley B. Towards a balanced scorecard: A critical analysis of the Culture and Sport Evidence (CASE) programme. Cultural Trends. 2012;21(4):325-34.

6. Dimitropoulos P, Kosmas I, Douvis I. Implementing the balanced scorecard in a local government sport organization: Evidence from Greece. International Journal of Productivity and Performance Management. 2017;66(3):362-79.

7. Papadimitriou D, Taylor P. Organisational effectiveness of Hellenic national sports organisations: A multiple constituency approach. Sport Management Review. 2000;3(1):23-46.

8. Shilbury D, Moore KA. A study of organizational effectiveness for national Olympic sporting organizations. Nonprofit and Voluntary Sector Quarterly. 2006;35(1):5-38.

9. Eydi H, Ramzaninezgad R, Yosefi B, Malekakhlagh E. Introducing Questionnaire of Effectiveness in Sporting Federations According to Competing Value Framework. Sport Management Studies. 2014;6(22):63-84 [Article in Farsi].

10. Honari H, Mohammadi L, Ghafori F, Afshari M. The Application of PCA Method to Evaluating the Performance of Sports Federations Based on EFQM Approaches. New Trends in sport Management. 2013;1(2):19-29 [Article in Farsi].

11. Mirfakhredini H, Peymanfar MH, Oghada AK, Alimohammadi H. Performance Assessment of Sports Organization with BSC - Topsis Integrated Model. Journal of Sport Management. 2013;5(16):77-96 [Article in Farsi].

12. NezadSajjadi SA, SoleimaniDamaneh J. Identify and Prioritize the Criteria of Performance Evaluation of Iranian Sport Federation Form Expert Point of View Sing the AHP Model. Sport Management Studies. 2014;6(23):17992 [Article in Farsi].

13. Solntsev I, Osokin N. Designing a performance measurement framework for regional networks of national sports organizations: evidence from Russian football. Managing Sport and Leisure. 2018:1-21.

14. Torres L, Martin E, Guevara JC. The gold rush: Analysis of the performance of the Spanish Olympic federations. Cogent Social Sciences. 2018;4(1):1446689.

15. O'Boyle I, Hassan D. Performance management and measurement in national-level non-profit sport organisations. European Sport Management Quarterly. 2014;14(3):299-314.

16. Geeraert A, Alm J, Groll M. Good governance in international sport organizations: an analysis of the 35 Olympic sport governing bodies. International Journal of Sport Policy and Politics. 2014;6(3):281-306.

17. Nagel S, Schlesinger T, Bayle E, Giauque D. Professionalisation of sport federations - a multi-level framework for analysing forms, causes and consequences. European Sport Management Quarterly. 2015;15(4):407-33.

18. Ruoranen K, Klenk C, Schlesinger T, Bayle E, Clausen J, Giauque D, et al. Developing a conceptual framework to analyse professionalization in sport federations. European Journal for Sport and Society. 2016;13(1):55-74.

19. O'Boyle I. Developing a performance management framework for a national sport organisation. Sport management review. 2014;18(2):308-16.

20. Glaser BG. Basics of grounded theory analysis: Emergence vs forcing: Sociology press; 1992.

21. Neergaard MA, Olesen F, Andersen RS, Sondergaard J. Qualitative description-the poor cousin of health research? BMC medical research methodology. 2009;9(1):52.

22. Holt NL, Pankow K, Tamminen KA, Strachan L, MacDonald DJ, Fraser-Thomas J, et al. A qualitative study of research priorities among representatives of Canadian Provincial Sport Organizations. Psychology of Sport and Exercise. 2018;36:8-16.

23. Schulenkorf N. Managing sport-for-development: Reflections and outlook. Sport Management Review. 2017;20(3):243-51.

24. Schulenkorf N, Sherry E, Rowe K. Sport for development: An integrated literature review. Journal of Sport Management. 2016;30(1):22-39.

25. Rowe K, Karg A, Sherry E. Community-oriented practice: Examining corporate social responsibility and development activities in professional sport. Sport Management Review. 2018. 
26. Carlsson-Wall M, Kraus K, Messner M. Performance measurement systems and the enactment of different institutional logics: insights from a football organization. Management Accounting Research. 2016;32:45-61.

27. Wemmer F, Emrich E, Koenigstorfer J. The impact of coopetition-based open innovation on performance in nonprofit sports clubs. European Sport Management Quarterly. 2016;16(3):341-63.

28. Pasban M, Nojedeh SH. A Review of the Role of Human Capital in the Organization. Procedia - Social and Behavioral Sciences. 2016;230:249-53.

29. Lastra R, Bell P, Bond C. Sports betting and the integrity of Australian sport: Athletes' and non-athletes' perceptions of betting-motivated corruption in sport. International Journal of Law, Crime and Justice. 2018;52:185-98.

30. Siguencia LO, Herman D, Marzano G, Rodak P. The Role of Social Media in Sports Communication Management: An Analysis of Polish Top League Teams' Strategy. Procedia Computer Science. 2017;104:73-80.

31. Shakerian H, Dehnavi HD, Ghanad SB. The Implementation of the Hybrid Model SWOT-TOPSIS by Fuzzy Approach to Evaluate and Rank the Human Resources and Business Strategies in Organizations (Case Study: Road and Urban Development Organization in Yazd). Procedia - Social and Behavioral Sciences. 2016;230:307-16. 